\title{
Manejo de Merremia aegyptia com misturas de herbicidas utilizando diferentes lâminas de água e na presença ou ausência de palha de cana-de-açúcar ${ }^{1}$
}

\author{
Management of Merremia aegyptia with mixtures of herbicides under different \\ rainfall simulation and in in the presence and absence of sugarcane straw
}

\author{
Patricia Andrea Monquero², Erika Nascimento Braga ${ }^{3}$, Marcelo Rafael Malardo ${ }^{4}$
}

\begin{abstract}
Resumo - A alta frequência de Merremia aegyptia nos canaviais colhidos de forma mecânica está relacionada à sua adaptação a esse sistema de colheita, o que resultou em um aumento do potencial de infestação dessa espécie em relação a outras plantas daninhas. O objetivo deste trabalho foi avaliar o manejo de $M$. aegyptia pela aplicação de herbicidas em pré-emergência na presença e ausência de palha em solo argiloso submetido a diferentes lâminas de água. Dois experimentos foram realizados no delineamento inteiramente casualizado, com quatro repetições. Em cada experimento foi avaliado uma mistura de herbicida: mesotrione + atrazine $\left(0,25+3,0\right.$ L i.a. ha $\left.^{-1}\right)$ e diuron + hexazinone + sulfometuron-methyl $\left(1386+391+33,35 \mathrm{~g} \mathrm{i}\right.$. ha $\left.{ }^{-1}\right)$. Os tratamentos foram arranjados em esquema fatorial $8 \times 2 \times 2$, sendo oito profundidades avaliadas $(0,5,10,15,20,25,30$ e 35 $\mathrm{cm}$ ), duas coberturas (com e sem palha) e duas lâminas de agua após a aplicação dos herbicidas $(20$ e $40 \mathrm{~mm}$ ). Os herbicidas foram aplicados sobre colunas preenchidas com solo de textura argilosa com 0 e com $10 \mathrm{t} \mathrm{ha}^{-1}$ de palha sobre a superfície dos canos e que posteriormente foram colocadas em simulador de chuva. Após a irrigação, as colunas foram abertas longitudinalmente e mantidas em casa-de-vegetação por 72 horas. A semeadura da M. aegyptia (planta alvo) foi feita em espaços de $5 \mathrm{~cm}$ no centro de cada parte da coluna. A associação mesotrione + atrazine apresentou controle em maior profundidade de $M$. aegyptia com $40 \mathrm{~mm}$ de precipitação $(23 \mathrm{~cm})$ no tratamento com ausência de palha. O diuron + hexazinone + sulfometuron-methyl apresentou controle até próximo a $15 \mathrm{~cm}$ de profundidade em ambas simulações de chuva e a palha apresentou pouca interferência na ação da mistura.
\end{abstract}

Palavras-chaves: corda-de-viola, controle químico, lixiviação, percolação

\begin{abstract}
The high frequency of M. aegyptia in sugarcane harvested mechanically is related to its adapting behavior to this harvesting system, what resulted in an increased the infestation potential of this species in relation to other weeds. The aim of this study was to evaluate the management $M$. aegyptia by spraying pre-emergence herbicides, in the presence and absence of straw in clay soil, under different rainfall simulation. Two experiments were carried out in a completely randomized design with four replications. In each experiment was evaluated the

\footnotetext{
${ }^{1}$ Recebido para publicação em 12/11/2014 e aceito em 15/07/2015.

2 Professora Associada do Centro de Ciência Agrárias/UFScar. Departamento de Recursos Naturais e Proteção Ambiental. Rodovia Anhanguera, km 174. Araras, SP. E-mail: pamonque@cca.ufscar.br

3 Aluna de graduação do curso de engenharia agronômica do CCA/UFSCar - bolsista FAPESP. E-mail: erikanbraga@gmail

${ }^{4}$ Aluno de graduação do curso de engenharia agronômica do CCA/UFSCar . E-mail: marcelo.malardo@ hotmail.com
} 
mixtures of herbicides: mesotrione + atrazine $\left(0.25+3.0 \mathrm{~L}\right.$ ai ha $\left.{ }^{-1}\right)$ and diuron + hexazinone + sulfometuron-methyl $\left(1386+391+33.35 \mathrm{~g} \mathrm{i} \mathrm{ha}^{-1}\right)$. The treatments were arranged in factorial $8 \mathrm{x}$ $2 \times 2$ design, composed by eight evaluated depths $(0,5,10,15,20,25,30$ and $35 \mathrm{~cm})$, two covers (with or without straw) and two rainfall simulation after herbicide application (20 and $40 \mathrm{~mm}$ ). Herbicides were applied to columns filled with clay soil and with 0 and $10 \mathrm{t} \mathrm{ha}^{-1}$ of straw coverage. After herbicide application, the columns were placed under simulated rainfall during the time necessary to apply the equivalent of 20 and $40 \mathrm{~mm}$ of rain. After this process, the columns remained for 72 hours in the horizontal position and opened longitudinally to sowing M. aegyptia (target plant). Mesotrione + atrazine presented, in greater depth $(23 \mathrm{~cm})$, control of M. aegyptia under 40 $\mathrm{mm}$ rainfall and the ineffective control under $20 \mathrm{~mm}$ of precipitation with or without straw. Diuron + hexazinone + sulfometuron had control until close to $15 \mathrm{~cm}$ depth in both rainfall simulations and the straw had little interference in the action of this mixture.

Keywords: morning glory, chemical control, leaching, percolation

\section{Introdução}

A presença de plantas daninhas nas áreas de cultivo de cana-de-açúcar é considerada um dos principais problemas do sistema produtivo da cultura. Estudos da interferência de plantas daninhas na cana-de-açúcar relataram perdas de produtividade de $82 \%$ devido a competição com Urochloa decumbens (Kuva et al., 2001) e 33\% devido a infestação mista de Panicum maximum e diferentes espécies de folhas largas (Meirelles et al., 2009).

Dentre as espécies de folhas largas frequentes em canaviais destaca-se Merremia aegyptia, conhecida popularmente por cordade-viola (Kuva et al., 2007). Segundo Azania et al. (2009), para o controle de Ipomoea spp e Merremia spp ser considerado eficiente são necessárias duas aplicações de herbicida, uma após a colheita e outra aos 100 a 120 dias após a primeira pulverização, situação que depende do monitoramento e metodologia específica para o controle dessas plantas infestantes.

O controle destas plantas daninhas em área com colheita mecanizada de cana-deaçúcar pode ser dificultado porque a presença da camada de palha sobre o solo afeta a dinâmica dos herbicidas. Segundo Prata et al. (2003), o movimento descendente dos herbicidas no solo é influenciado pela interação entre sua característica fisico-química (solubilidade, koc, kow e pka) com o solo (matéria orgânica, tamanho e distribuição dos colóides e poros, densidade e $\mathrm{pH}$ ), e regime pluviométrico.

Para herbicidas de elevada adsorção, o conteúdo de matéria orgânica do solo deve ser considerado, pois quanto mais alto, maior é a adsorção do herbicida, consequentemente menor a lixiviação. Em solos arenosos, a lixiviação será ainda maior do que em solos siltosos ou argilosos (Prata et al., 2003). Em solos com baixo teor de matéria orgânica e CTC efetiva, verificou-se, por exemplo, o aumento na ocorrência de efeitos fitotóxicos do smetolachlor às culturas e na probabilidade de contaminação de águas subterrâneas (Procópio et al., 2001).

Quando um herbicida é aplicado sobre a palha, é interceptado pela superfície desta e torna-se vulnerável à volatilização e/ou fotólise. O transporte de herbicidas da palha para o solo dependente da capacidade da palha de cobrir o solo e reter esses herbicidas, das características físico-químicas do herbicida, e do período em que a área permanece sem chuva após a aplicação (Carbonari et al., 2010).

A lixiviação é fundamental para a incorporação superficial da maioria dos herbicidas, atingindo sementes ou plantas em germinação, mas, quando excessiva, pode carreá-los para camadas mais profundas do solo, limitando sua ação e podendo, inclusive, promover contaminação do lençol freático. Monquero et al. (2008), verificaram que após 20 
mm de chuva, o herbicida trifloxysulfuromsodium + ametryn provocou sintomas decrescentes de fitotoxicidade em plântulas de pepino que emergiram de 0 a $20 \mathrm{~cm}$; já para os herbicidas diuron+ hexazinone e imazapyr o efeito foi observado até $10 \mathrm{~cm}$. Por sua vez, a precipitação de $40 \mathrm{~mm}$ fez com que as misturas diuron + hexazinone provocassem injúrias severas nas plantas de pepino até $15 \mathrm{~cm}$ de profundidade. Os herbicidas trifloxysulfurom-sodium + ametryn e imazapyr foram detectados até $20 \mathrm{~cm}$ de profundidade. Com $80 \mathrm{~mm}$ de simulação de chuva, o herbicida diuron + hexazinone causou fitotoxicidade até $35 \mathrm{~cm}$, e os herbicidas trifloxysulfurom-sodium + ametryn, imazapyr até $25 \mathrm{~cm}$ de profundidade.

Tendo em vista o efeito da palha de cana-de-açúcar no sistema de produção, este trabalho teve como objetivo avaliar o manejo de M. aegyptia pela aplicação de herbicidas em pré-emergência na presença e ausência de palha em solo argiloso submetido a diferentes lâminas de água.

\section{Material e Métodos}

Os experimentos foram realizados em casa-de-vegetação do Centro de Ciências Agrárias (CCA), da Universidade Federal de São Carlos (UFSCar), em Araras, SP. O CCA encontra-se entre as coordenadas geográficas de $22^{\circ} 21^{\prime} 25^{\prime \prime} \mathrm{S}$ e $47^{\circ} 23^{\prime} 03^{\prime \prime} \mathrm{W}$, e altitude de $629 \mathrm{~m}$. Amostras de solo foram retiradas de um solo classificado como Latossolo Vermelho Distrófico com textura argilosa (Embrapa, 1999), até a profundidade de $40 \mathrm{~cm}$. Os resultados da análise química e física podem ser observados na Tabela 1.

Tabela 1: Análises química e física das amostras de solo utilizada

\begin{tabular}{cccccccccccccc}
\hline \multicolumn{110}{c}{ Latossolo Vermelho Distrófico } \\
\hline $\mathrm{P}$ & M.O. & $\mathrm{pH}$ & $\mathrm{K}$ & $\mathrm{Ca}$ & $\mathrm{Mg}$ & $\mathrm{H}+\mathrm{Al}$ & $\mathrm{Al}$ & $\mathrm{SB}$ & $\mathrm{CTC}$ & $\mathrm{V}$ & Argila & Areia & Silte \\
\hline $\mathrm{mg} / \mathrm{dm}^{3}$ & $\mathrm{~g} / \mathrm{dm}^{3}$ & $\mathrm{Ca} \mathrm{CI}_{2}$ & $\mathrm{mmol}_{\mathrm{c}} / \mathrm{dm}^{3}$ & & & $\%$ & & & $\%$ & & $\mathrm{~g} \mathrm{~kg}^{-1}$ & \\
\hline 15 & 24 & 5,1 & 2,5 & 28 & 12 & 40 & 0,4 & 42,5 & 82,5 & 52 & 660 & 150 & 190 \\
\hline
\end{tabular}

Dois experimentos foram realizados em delineamento inteiramente casualizado, com quatro repetições. Em cada experimento foi avaliado uma mistura de herbicida: mesotrione + atrazine $\left(0,25+3,0\right.$ L i.a. ha $\left.{ }^{-1}\right)$ e diuron + hexazinone + sulfometuron $(1386+391+33,35$ g i. $\left.\mathrm{ha}^{-1}\right)$. Os tratamentos foram arranjados em esquema fatorial $8 \times 2 \times 2$, sendo oito profundidades avaliadas $(0,5,1015,20,25,30$ e $35 \mathrm{~cm}$ ), duas coberturas (com e sem palha) e duas lâminas de agua após a aplicação dos herbicidas (20 e $40 \mathrm{~mm}$ ).

As unidades experimentais foram constituídas de colunas de PVC de $10 \mathrm{~cm}$ de diâmetro e $40 \mathrm{~cm}$ de comprimento, preenchidas com solo argiloso. Os tubos foram envoltos internamente por uma camada de parafina a fim de evitar escorrimento lateral da solução do solo. Na parte basal, para reter o solo e permitir a drenagem, foram colocadas telas de sombrite $50 \%$. As colunas de solo foram, então, submetidas à irrigação por capilaridade, até se apresentar saturado no topo. Após isto, os canos foram colocados em um suporte e suspensos, permitindo-se desta forma, o escoamento da água durante 48 horas para restaurar sua capacidade de campo.

Os herbicidas foram aplicados em duas situações distintas, a primeira sobre uma camada correspondente a $10 \mathrm{t} \mathrm{ha}^{-1}$ de palha de cana colocada no topo de cada coluna, e nesses tratamentos foram acopladas peças de PVC de $10 \mathrm{~cm}$ de diâmetro com altura suficiente para acondicionar esse material. $\mathrm{Na}$ segunda situação, às aplicações foram realizadas diretamente no solo (sem a presença de palha). As misturas dos herbicidas foram aplicadas com pulverizador costal pressurizado com $\mathrm{CO}_{2}$, 
provido de barra de pulverização contendo dois bicos tipo leque Teejet 110.02 e com volume de aplicação de 200L ha-1. No momento da aplicação a velocidade do vento, temperatura e umidade do ar foram de $0,3 \mathrm{~ms}^{-1}, 26^{\circ} \mathrm{C}$ e $30 \%$.

Um dia após a aplicação dos herbicidas, os tubos foram colocados sob simulador de chuva, com intensidade de precipitação de $1 \mathrm{~mm}$ $\mathrm{min}^{-1}$, durante o tempo necessário para aplicar as lâminas de água de 20 e $40 \mathrm{~mm}$. Após este processo, as colunas permaneceram em repouso por 72 horas. Os tratamentos que receberam 10 $\mathrm{t} \mathrm{ha}^{-1}$ de palha, tiveram a estrutura acoplada ao cano de PVC retirada cuidadosamente juntamente com a palha, segundo metodologia proposta por Hixson (2008) e então todas as colunas (com palha e sem palha), foram colocadas na posição horizontal e abertas longitudinalmente. Cada coluna foi dividida em oito seções de $5 \mathrm{~cm}$, medidas a partir da superfície onde os herbicidas foram aplicados. Em cada seção foi semeada uma linha contínua de sementes de $M$. aegyptia.

Aos 7, 14 e 21 dias após emergência (DAE), foram avaliadas visualmente possíveis alterações nas plântulas caracterizadas como efeitos fitotóxicos dos herbicidas. Estas avaliações foram baseadas em critérios qualitativos, segundo ALAM (1974), com escala percentual de notas, onde 0 (zero) corresponde a nenhuma injúria na planta e 100 (cem) a morte das plantas. Aos 21 DAE foi determinada a massa da matéria seca da parte aérea das plantas, para isto, as plantas foram cortadas rente ao colo e o material colhido foi seco em estufa com circulação forçada de ar (65 $\pm 2{ }^{\circ} \mathrm{C}$ ) por 72 horas.

Os dados obtidos para cada um dos herbicidas foram submetidos à análise de variância pelo teste $\mathrm{F}$, e as médias comparadas por meio do teste de Tukey a $5 \%$ de probabilidade, utilizando-se o programa estatístico computacional ASSISTAT. Quando significativos, os resultados foram analisados com o emprego de regressões não lineares.

\section{Resultados e Discussão}

A fitotoxicidade de diuron + hexazinone + sulfometuron-methyl em M. aegyptia com 20 e $40 \mathrm{~mm}$ de precipitação pode ser observada na Figura 1. Observa-se evolução da fitotoxicidade com o passar do tempo em todos os tratamentos, sendo que aos $21 \mathrm{DAE}$, a fitotoxicidade foi igual ou maior que $80 \%$ até próximo a $15 \mathrm{~cm}$ de profundidade, independente da umidade e da presença de palha. Os sintomas observados foram de clorose e necrose nas internervuras e bordas foliares nas plântulas presentes em menor profundidade e redução inicial do porte e posterior necrose nas plântulas que oriundas das sementes colocadas em maior profundidade. Estes sintomas são clássicos dos inibidores do FSII e de ALS, respectivamente (Zhou et al., 2007; Vidal; Merotto Jr, 2001).

Garcia et al. (2012) verificaram que para o solo de textura argilosa, os herbicidas diuron + hexazinone + sulfometuron-methyl e hexazinone atingiram aproximadamente 10 e 13 $\mathrm{cm}$ de profundidade com simulação de 0 e 40 $\mathrm{mm}$, respectivamente. Os mesmos autores verificaram que estes herbicidas proporcionaram $80 \%$ de controle de Ipomoea triloba para a profundidade de $10 \mathrm{~cm}$ no solo de textura argilosa, independente da precipitação.

Com plantas bioindicadoras, Cason et al. (2010) observaram que com a simulação de 20 $\mathrm{mm}$ de precipitação em solo de textura argilosa, a mistura diuron + hexazinone + sulfometuronmethyl provocou fitotoxicidade de aproximadamente $80 \%$ até os $20 \mathrm{~cm}$ de profundidade. Quando a simulação foi de 40 $\mathrm{mm}$, os autores observaram maior lixiviação desse herbicida, que provocou essa mesma porcentagem de controle, até $25 \mathrm{~cm}$ de profundidade. Importante ressaltar que dos três ingredientes ativos desta mistura, o hexazinone apresenta alta solubilidade em água $(29.800$ ppm a $25^{\circ} \mathrm{C}$ ), necessitando de pouca umidade para se movimentar e atuar (Bouchard et al., 1985). 

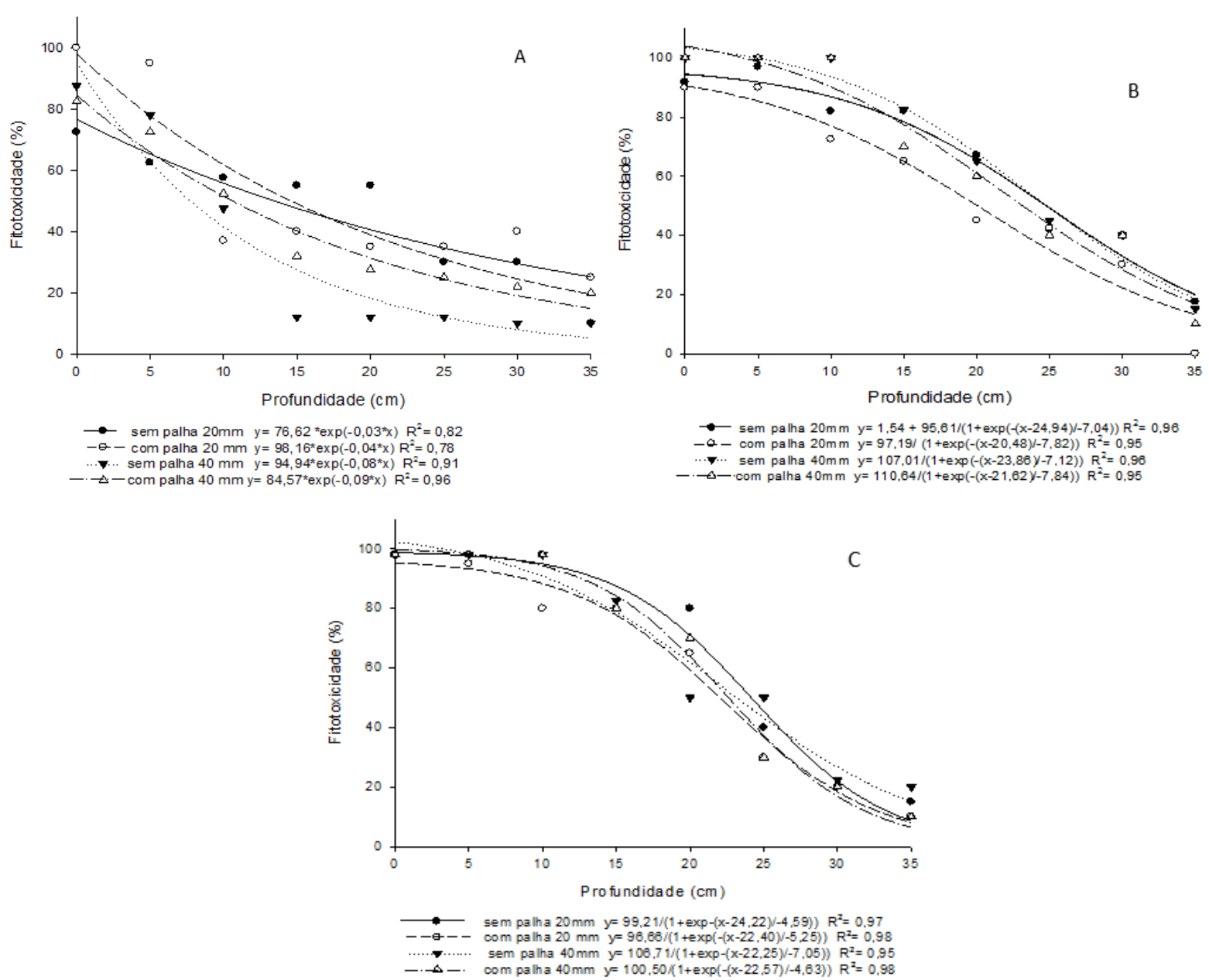

Figura 1. Porcentagem de fitotoxicidade de diuronthexazinone+sulfometuron-methyl em $M$. aegyptia após aplicação em solo argiloso com ou sem palha com simulação de 20 e $40 \mathrm{~mm}$ de chuva aos 7 (A), 14 (B) e 21(C) DAE.

Em relação a fitotoxicidade de $M$. aegyptia provocada pelo uso de mesotrione + atrazine (Figura $2 \mathrm{~A}-\mathrm{C}$ ) com $20 \mathrm{~mm}$ de precipitação houve pouca diferença entre os manejos com e sem palha, sendo verificado controle igual ou superior a $80 \%$ até $11 \mathrm{~cm}$ de profundidade com palha e $14 \mathrm{~cm}$ no tratamento sem palha. Quando a precipitação foi de $40 \mathrm{~mm}$ houve maior diferença entre o controle com ou sem palha. Maior fitotoxicidade foi observada com o tratamento sem palha e $40 \mathrm{~mm}$ de chuva (controle até $23 \mathrm{~cm}$ de profundidade) após a aplicação dos herbicidas, sendo que o controle variou de 100 a $55 \%$ aos 0 e $35 \mathrm{~cm}$ de profundidade, respectivamente. A presença de palha na superfície no momento da aplicação reteve parte do herbicida, o qual apresentou fitotoxicidade igual ou maior a $80 \%$ até a profundidade de $12 \mathrm{~cm}$. Segundo Orzari et al. (2013), M. aegyptia pode apresentar germinação em profundidades maiores no solo, chegando até a $20 \mathrm{~cm}$. Os autores também ressaltam que a partir da profundidade de $10 \mathrm{~cm}$ apenas algumas plantas emergiram, porém apresentavam-se cloróticas e, consequentemente, mais suscetíveis a qualquer método de manejo.

$A$ adição de baixas doses de atrazine com mesotrione em aplicações de pósemergência causa um efeito sinergístico no controle de algumas plantas consideradas 
difíceis, inclusive para algumas plantas daninhas perenes (Armel et al., 2000a, 2000b). Alguns pesquisadores têm sugerido que o aumento da atividade herbicida da mistura de inibidores da HPPD com inibidores do fotossistema II (PSII) resulta da inter-relação entre seus modos de ação; entretanto, nenhum autor tem reportado como a atrazine afeta a absorção, translocação ou o metabolismo dos inibidores da HPPD (Abendroth et al., 2006). Neste trabalho, observou-se que quando usado em pré-emergência a mistura de mesotrione+ atrazine também foi eficiente para o controle de $M$. aegyptia, entretanto, houve influência da presença de palha e umidade.
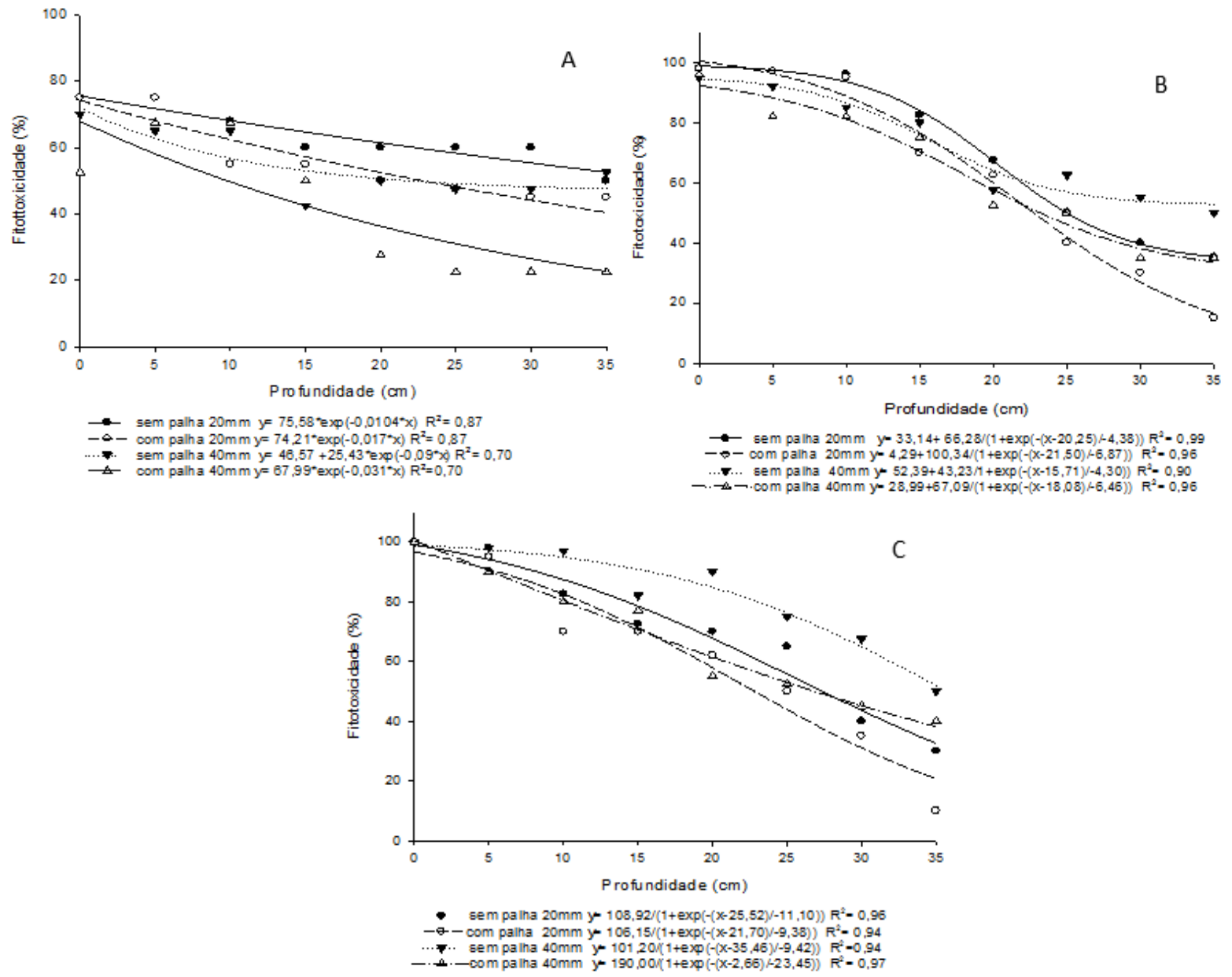

Figura 2. Porcentagem de fitotoxicidade de mesotrione + atrazine em $M$. aegyptia em solo argiloso com ou sem palha com simulação de 20 e $40 \mathrm{~mm}$ de chuva aos 7 (A), 14 (B) e 21(C) DAE.

De acordo com Jone e Griffin (2008), em canavial localizado no estado de Louisiana, EUA, os herbicidas atrazine e a mistura diuron + hexazinone quando usados em préemergência para o controle de Ipomoea coccinea (espécie também da família Convolvulaceae) resultaram em controle inicial acima de $90 \%$. Contudo, as notas decresceram para menos de $50 \%$ aos 77 dias após a aplicação dos herbicidas, em virtude da emergência de novas plantas nas parcelas. Da mesma forma, Correia et al. (2010) verificaram que a associação de mesotrione aos herbicidas atrazine, metribuzin e diuron + hexazinone foi 
mais eficaz no controle de $M$. aegyptia do que quando aplicado sozinho, o que corrobora com os dados de fitotoxicidade deste trabalho, principalmente no tratamento sem palha e com $40 \mathrm{~mm}$ de chuva que apresentou $100 \%$ de controle da menor profundidade.

Com relação a massa da matéria seca da parte aérea de $M$. aegyptia, com o uso de mesotrione + atrazine, observa-se, que os maiores valores foram observados nas maiores profundidades, demonstrando a limitação da lixiviação deste herbicida nos tratamentos com $20 \mathrm{~mm}$ de chuva com e sem palha ou com 40 $\mathrm{mm}$ mas com a presença de palha (Tabela 2 ).

Tabela 2 - Massa da matéria seca da parte aérea de $M$. aegyptia submetida às misturas mesotrione + atrazine e diuron + hexazinone + sulfometuron-methyl com simulação de 20 e $40 \mathrm{~mm}$ de chuva em solo argiloso aos 21 DAE.

\begin{tabular}{|c|c|c|c|c|}
\hline & \multicolumn{4}{|c|}{ Mesotrione + atrazine } \\
\hline & \multicolumn{2}{|c|}{ Com Palha } & n Palha & \\
\hline & \multicolumn{4}{|c|}{ Precipitação (mm) } \\
\hline Profundidade $(\mathrm{cm})$ & 20 & 40 & 20 & 40 \\
\hline 0 & $0,00 \mathrm{c}$ & $0,00 \mathrm{a}$ & $0,01 \mathrm{~b}$ & $0,00 \mathrm{c}$ \\
\hline 5 & $0,03 \mathrm{bc}$ & $0,05 \mathrm{a}$ & $0,07 \mathrm{a}$ & $0,01 \mathrm{c}$ \\
\hline 10 & $0,03 \mathrm{bc}$ & $0,04 \mathrm{a}$ & $0,09 \mathrm{a}$ & $0,03 \mathrm{c}$ \\
\hline 15 & $0,05 \mathrm{ab}$ & $0,05 \mathrm{a}$ & $0,05 \mathrm{ab}$ & $0,04 \mathrm{~b}$ \\
\hline 20 & $0,08 \mathrm{a}$ & $0,06 \mathrm{a}$ & $0,07 \mathrm{a}$ & $0,08 \mathrm{a}$ \\
\hline 25 & $0,07 \mathrm{a}$ & $0,10 \mathrm{a}$ & $0,05 \mathrm{a}$ & $0,09 \mathrm{a}$ \\
\hline 30 & $0,09 \mathrm{a}$ & $0,10 \mathrm{a}$ & $0,07 \mathrm{a}$ & $0,05 \mathrm{~b}$ \\
\hline 35 & $0,09 \mathrm{a}$ & $0,09 \mathrm{a}$ & $0,08 \mathrm{a}$ & $0,09 \mathrm{a}$ \\
\hline DMS (5\%) & 0,04 & 0,14 & 0,05 & 0,03 \\
\hline \multirow[t]{4}{*}{$\mathrm{CV}(\%)$} & 33,12 & 55,24 & 32,66 & 45,94 \\
\hline & \multicolumn{4}{|c|}{ Diuron + hexazinone + sulfometuron } \\
\hline & \multicolumn{2}{|c|}{ Com Palha } & \multicolumn{2}{|c|}{ Sem Palha } \\
\hline & \multicolumn{4}{|c|}{ Precipitação (mm) } \\
\hline Profundidade $(\mathrm{cm})$ & 20 & 40 & 20 & 40 \\
\hline $0-5$ & $0,00 \mathrm{~b}$ & $0,00 \mathrm{~b}$ & $0,00 \mathrm{~b}$ & $0,00 \mathrm{~b}$ \\
\hline $5-10$ & $0,00 \mathrm{~b}$ & $0,00 \mathrm{~b}$ & $0,00 \mathrm{~b}$ & $0,00 \mathrm{~b}$ \\
\hline $10-15$ & $0,07 \mathrm{a}$ & $0,08 \mathrm{a}$ & $0,05 \mathrm{ab}$ & $0,08 \mathrm{a}$ \\
\hline $15-20$ & $0,10 \mathrm{a}$ & $0,09 \mathrm{a}$ & $0,04 \mathrm{ab}$ & $0,12 \mathrm{a}$ \\
\hline $20-25$ & $0,09 \mathrm{a}$ & $0,11 \mathrm{a}$ & $0,12 \mathrm{a}$ & $0,11 \mathrm{a}$ \\
\hline $25-30$ & $0,11 \mathrm{a}$ & $0,13 \mathrm{a}$ & $0,13 \mathrm{a}$ & $0,13 \mathrm{a}$ \\
\hline $30-35$ & $0,09 \mathrm{a}$ & $0,15 \mathrm{a}$ & $0,13 \mathrm{a}$ & $0,15 \mathrm{a}$ \\
\hline $35-40$ & $0,12 \mathrm{a}$ & $0,07 \mathrm{a}$ & $0,11 \mathrm{a}$ & $0,07 \mathrm{a}$ \\
\hline DMS (5\%) & 0,12 & 0,12 & 0,09 & 0,12 \\
\hline $\mathrm{CV}(\%)$ & 36,45 & 24,18 & 13,14 & 45,74 \\
\hline
\end{tabular}

Teste de Tukey a 5\%. DMS: diferença mínima significativa; CV: coeficiente de variação.Obs.: letras iguais indicam que, o nível de $5 \%$ de significância, não há diferença entre as médias.

O uso de diuron+ hexazinone + precipitação e sem palha com 20 e $40 \mathrm{~mm}$ de sulfometuron-methyl proporcionou diferenças nos tratamentos com palha e $40 \mathrm{~mm}$ de menores valores de massa da matéria seca foram 
encontrados na profundidade de $0-10 \mathrm{~cm}$ (Tabela 2).

Kaufmann et al. (2012) registraram em um Argissolo Vermelho Amarelo com 3\% de argila, $73 \%$ de silte e $24 \%$ de areia maior concentração de atrazine e de diuron na profundidade de $5 \mathrm{~cm}$ após uma precipitação aplicada de $15 \mathrm{~mm}$ e também verificaram a presença dos herbicidas no solo por mais de 100 dias, o que poderia contribuir no controle de novos fluxos de emergência de plantas daninhas, o que é importante para espécies que podem apresentar sementes dormentes, como é o caso de M. aegyptia.

\section{Conclusões}

A eficiência da mistura de herbicidas mesotrione + atrazine no controle de $M$. aegyptia foi influenciada pela palha de cana-de-açúcar e a lâmina de água aplicada, com maior controle da planta daninha em solo sob aplicação de $40 \mathrm{~mm}$ de precipitação $(23 \mathrm{~cm})$. O diuron+ hexazinone + sulfometuron-methyl controlou até a faixa de $15-20 \mathrm{~cm}$ de profundidade no solo argiloso, independente da presença de palha e da quantidade de chuva simulada.

\section{Referências}

ABENDROTH, J.A.; MARTIN, A.R.; ROETH, F.W. Plant response to combinations of mesotrione and photosystem II inhibitors. Weed Techn., v. 20, n.1, p.267-274. 2006.

ARMEL, G.R.; WILSON, H.P.; HINES, T.E. Control of two perennial weeds with ZA 1296. Proc. N. Cent. Weed Sci. Soc. v.55, p. 47-48, 2000a.

ARMEL, G.R.; WILSON, H.P.; HINES, T.E. Response of two perennial weeds to ZA 1296. Weed Sci. Soc. Am. Abstr. v.40, p.110-111, 2000b.

ASOCIATION LATINOAMERICANA DE MALEZAS. Recomendaciones sobre unificación de los sistemas de evaluación em ensayos de control de malezas. ALAM, Bogotá, v. 1, p. 35-38, 1974.

AZANIA, C.M. et al. Manejo químico de Convolvulaceae e Euphorbiaceae em cana-deaçúcar em período de estiagem. Planta Daninha, v.27, n.4, p.841-848, 2009.

BOUCHARD, D.C.; LAVY, T.L.; LAWSON, E.R. Mobility and persistence of hexazinone in a forest watershed. Journal of Environmental Quality, v.14, n.2, p.229-233, 1985.

CARBONARI, C.A. et al. Efeitos de períodos de permanência de clomazone + hexazinona no solo e na palha de cana-de-açúcar antes da ocorrência de chuvas na eficácia de controle de plantas daninhas. Planta Daninha, v.28, n.1, p.197-205, 2010.

CASON, J.B. et al. Lixiviação e persistência de diuron+hexazinone+sulfometuron, hexazinone, sulfometuron e diuron. In: CONGRESSO BRASILEIRO DA CIÊNCIA DAS PLANTAS DANINHAS, 27., Ribeirão Preto, 2010. Resumos... Ribeirão Preto: SBCPD, 2010. p.3396-3400.

CORREIA, N.M.; BRAZ, B.A.; FUZITA, W.E. Eficácia de herbicidas aplicados nas épocas seca e úmida para o controle de Merremia aegyptia na cultura da cana-de-açúcar. Planta Daninha, v.28, n.3, p.631-642, 2010.

EMBRAPA. Sistema brasileiro de classificação de solos. Brasília: Embrapa, 1999. 412p.

GARCIA, D.B. et al. Lixiviação de diuron, hexazinone e sulfometuron-methyl em formulação comercial e isoladamente em dois solos contrastantes. Revista Brasileira de Herbicidas, v.11, n.2, p.222-230, 2012.

HIXSON, A.C. Soil properties affect simazine and saflufenacil fate, behavior, and performance. $242 \mathrm{f}$. Dissertação (Mestrado em Fitotecnia) - North Carolina State University, 2008.

JONES, C.A.; GRIFFIN, J.L. Residual red morningglory (Ipomoea coccinea) control with 
foliar- and soil-applied herbicides. Weed Technology, v.22, n.3, p.402-407, 2008

KAUFMANN, V. et al. Transporte de atrazine e de diuron no perfil de um argissolo. Revista Brasileira de Recursos Hídricos, v.17, n.1, p.149-157, 2012.

KUVA, M.A. et al. Fitossociologia de comunidades de plantas daninhas em agroecossistema cana-crua. Planta Daninha, v.25, n.3, p.501-511, 2007.

KUVA, M.A. et al. Períodos de interferência das plantas daninhas na cultura da cana-deaçúcar. II Capim-braquiária (Brachiaria decumbens). Planta Daninha, v.19, n.3, p.323330, 2001.

MEIRELLES, G.L.S.; ALVES, P.L.C.A.; NEPOMUCENO, M.P. Determinação dos períodos de convivência da cana-soca com planta daninhas. Planta Daninha, v.27, n.1, p.67-73, 2009.

MONQUERO, P.A. et al. Potencial de lixiviação de herbicidas no solo submetidos a diferentes simulações de precipitação. Planta Daninha, v26, n.2, p.403-409, 2008.

ORZARI, I. et al. Germinação de espécies da família Convolvulaceae sob diferentes condições de luz, temperatura e profundidade de semeadura. Planta Daninha, v.31, n.1, p.53-61, 2013.

PRATA, F. et al. Glyphosate sorption and desorption in soils with different phosphorous levels. Scientia Agricola, v.60, n.1, p.175-180, 2003.

PROCÓPIO, S.O. et al. Efeito da irrigação inicial na profundidade de lixiviação do herbicida s-metolachlor em diferentes tipos de solo. Planta Daninha, v.19, n.3, p.409-417, 2001.

SOUZA, Z.M. et al. Sistemas de colheita e manejo da palhada de cana-de-açúcar. Pesquisa Agropecuária Brasileira, v.40, n.3, p.271-278, 2005.
VIDAL, R.A.; MEROTTO JR., A. Herbicidologia. Porto Alegre: Evangraf, 2001. $152 \mathrm{p}$.

ZHOU, Q. et al. Action mechanisms of acetolactate synthase-inhibiting herbicides. Pesticide Biochemistry and Physiology, v.89, n.2, p.89-96. 2007. 